\title{
Themes of Self-Regulation and Self-Exploration in the Life Stories of Religious American Conservatives and Liberals
}

\author{
Dan P. McAdams \\ Northwestern University \\ Kathrin J. Hanek \\ University of Michigan \\ Joseph G. Dadabo \\ Northwestern University
}

\begin{abstract}
A sample of 128 highly religious (Christian) midlife American adults completed a series of attitudinal and personality trait measures and narrated 12 important autobiographical scenes in their life stories. Individuals high on self-reported political conservatism tended to accentuate the theme of self-regulation in their life stories, repeatedly describing important autobiographical scenes wherein they struggled to control, discipline, manage, restrain, protect, or preserve the self. By contrast, individuals high on political liberalism tended to emphasize the theme of self-exploration, telling stories about expanding, discovering, articulating, or fulfilling the self. Demographics and dispositional traits (especially openness to experience) showed significant associations with conservatism-liberalism, as well, but these variables did not mitigate the robust relationship between life-narrative themes and political orientation. The results are discussed in terms of a broadened understanding of personality that conceives of dispositional traits and narrative identity as comprising distinct layers and complementary features of psychological individuality, both implicated in political lives.
\end{abstract}

KEY WORDS: conservatives, liberals, life stories, personality, self-regulation, self-exploration

The current study examines contrasting psychological themes in the life stories of American adults as they relate to self-reports of political orientation. Whereas recent studies have shown that political conservatives and liberals show correspondingly different personality traits and goals, very few studies have examined the personal narratives that conservatives and liberals construct to make meaning in their lives. In that a person's internalized life story may be viewed, like traits and goals, as an important feature of his or her personality (McAdams \& Pals, 2006), this study of thematic differences in life narratives aims to address the intricate relationship between personality and politics from a new perspective.

\section{Political Orientation and Three Layers of Personality}

Contemporary research on personality and political orientation suggests that conservatism and liberalism are associated with correspondingly different dispositional traits and psychological goals. 
For example, studies incorporating the Big Five taxonomy of personality traits suggest that individuals identifying themselves as relatively liberal show higher scores on the trait of openness to experience and lower scores on the trait of conscientiousness, compared to individuals who place themselves on the more conservative end of the political continuum (Carney, Jost, Gosling, \& Potter, 2008). Furthermore, the politeness facet of trait agreeableness may be associated with conservatism, whereas the compassion facet of agreeableness correlates with liberalism (Hirsh, DeYoung, Xu, \& Peterson, 2010). With respect to psychological goals, researchers have conceived of conservatism as motivated social cognition that serves to defend against death anxiety, system instability, uncertainty, and other epistemic and personal threats (Jost, Federico, \& Napier, 2009; Jost, Glaser, Kruglanski, $\&$ Sulloway, 2003). According to this perspective, politically conservative attitudes and beliefs function to satisfy psychological goals related to security, order, and self-esteem maintenance.

An emerging theoretical perspective in personality science contends that dispositional traits (like those encompassed within the Big Five framework) and psychological goals and motives (like those encompassed within the motivated social cognition approach) correspond roughly to two distinct layers of human personality (McAdams, 1996; McAdams \& Olson, 2010; McAdams \& Pals, 2006; Sheldon, Cheng, \& Hilpert, 2011; Singer, 2005). Whereas dispositional traits account for broad consistencies in how people behave across situations and over time (Costa \& McCrae, 1992), personal goals and motives address what people want (and fear) and how they strive to obtain what they want (and avoid what they fear) in particular social and developmental contexts and with respect to particular social roles (Emmons, 1999; Winter, 2007). Dispositional traits capture the perspective of the person as a social actor, expressing observable individual differences in the general ways actors perform on the social stage of everyday life. By contrast, motives and goals capture the person as a motivated agent, spelling out characteristic wants, desires, aims, intentions, aspirations, and aversions as they play out in particular contexts of a person's life. Whereas the inklings of dispositional traits (Layer 1 in personality) may be seen even in temperament differences expressed in infancy, personal goals and motives (Layer 2 in personality) begin to exert important effects in psychological individuality in late childhood and early adolescence (McAdams \& Olson, 2010; Mroczek \& Little, 2006).

For many people, a third layer of personality begins to form in late adolescence and young adulthood, a developmental period often labeled as emerging adulthood (Arnett, 2000). In response to the psychosocial challenge of finding an identity in the adult world of work and relationships (Erikson, 1968), emerging adults construct and internalize life stories-narrative reconstructions of the past and anticipations of the future that explain who I am, how I came to be, and where my life may be going in the future, within the norms, expectations, and scripts set forth in a given historical and cultural milieu (Hammack, 2008; McAdams, 1985, 2008; McLean, Pasupathi, \& Pals, 2007). A person's internalized and evolving life story-his or her narrative identity — forms the third layer of personality, constructed upon evolving personal goals and ever-present-yet-still-developing dispositional traits (McAdams \& Pals, 2006). If traits, then, describe the person as a social actor and goals tap into the person as a motivated agent, narrative identity speaks to the perspective of the person as an autobiographical author (McAdams \& Olson, 2010; McAdams \& Walden, 2010).

A person's narrative identity is an internalized and evolving story of the self that a person constructs in order to make sense of the remembered past, experienced present, and imagined future. The story contains reconstructed memories of high points, low points, and other self-defining memories in life, as well as imagined scenarios for the future (Singer, 2005). Like dispositional traits such as conscientiousness and openness to experience, narrative identity tracks individual differences in personality. But traits and stories tap into very different features of psychological individuality: traits capture dispositional features of personality encoded in semantic memory; internalized stories of the self capture narrative features of personality encoded in episodic memory (McAdams \& Olson, 2010). Trait terms spell out individual differences in recurrent social behaviors and reaction 
tendencies of social actors; narrative identity spells out differences in the language of narrative tone, theme, plot, and character. As such, traits are well designed to catalogue consistencies in social behavior whereas life stories are much better equipped to express personal meaning and identity.

What kinds of meanings might political conservatives and liberals express in narrative identity? Over the past decade, research on narrative identity has focused on a wide range of meanings, from emotional scripts such as redemption and contamination sequences to themes of agency, communion, generativity, and intrinsic growth (for reviews, see McAdams, 2008; McLean, 2008). It is clear that life-narrative accounts may be analyzed for many different kinds of psychological and social ideas. Drawing on a number of classic and current theories of political orientation, the current study focuses on the thematic dimension of self-regulation versus self-exploration. It is proposed that the life stories of American adults tending toward political conservatism should be structured around the theme of self-regulation, whereas the life stories of those tending toward political liberalism should feature the theme of self-exploration.

\section{Self-Regulation and Self-Exploration}

Going back to the psychodynamic formulations of Fromm (1947) and the authors of The Authoritarian Personality (Adorno, Frenkel-Brunswik, Levinson, \& Sanford, 1950), psychologists have tended to associate conservatism with strong concerns for self-regulation. Political conservatives may be more sensitive to and concerned with the problem of self-regulation in life-the challenge of taming, disciplining, restraining, controlling, regimenting, or monitoring the self's potentially egoistic or destructive impulses. Indeed, six of the nine cardinal features of the authoritarian personality as originally identified by Adorno et al. (1950) center on the problem of regulating impulses: Because they are disposed to believe that the world is brimming with wild and dangerous threats (1: "Projectivity"), including sexual goings on (2: "Sex"), authoritarians adhere strongly to conventional values (3: "Conventionalism") and submit uncritically to established authority (4: "Authoritarian Submission"), while condemning others who violate societal norms (5: "Authoritarian Aggression") and remaining suspicious of those creative and artistic expressions in human life that derive from deep feelings and irrational impulses (6: “Anti-Intraception"). Altemeyer's (1996) revised and streamlined conceptualization of right-wing authoritarianism maintains the strong emphasis on self-regulation as expressed in strict adherence to conventional rules and norms regarding impulse control and intolerance of those who seem to threaten those conventions. In the evocative words quoted by Bem (1970), individuals lying at the extreme right wing of the political continuum "do not like anything free and uncontrolled. They feel that people must be regulated within well-oiled machines" (p. 20).

Why might people with conservative political values favor self-regulation over the free expression of impulse in the stories of their lives? According to Tomkins $(1963,1987)$, it is because they do not trust human nature. Holding to what Tomkins described as a normative ideological script, conservatives tend to believe that human beings are basically evil or at best deeply flawed and therefore dangerous. They are suspicious of other people, especially those whose values do not seem to match their own values, and wary of the unbridled expression of human impulse. Accordingly, they embrace society's norms and commit to self-discipline, conventional achievement, and personal piety as ways of affirming control over a potentially explosive social world and over themselves. Their dogmatism, intolerance for ambiguity, and system-justification rationales serve to uphold the status quo while managing the threat posed by unregulated selves and uncontrollable worlds (Jost et al., 2003). Group life depends on obedience to norms and rules, which themselves are designed to rein in or sublimate the baser human instincts. Indeed, research suggests that conservatives, especially those with an authoritarian bent, do tend to see the world as a dangerous place (Weber \& Federico, 2007), filled with untrustworthy people and threatening ideas. 
From the conservative point of view, then, self-regulation-through personal discipline, submission to authority, and adherence to norms - promotes safety and security (Oesterreich, 2005). In The Conservative Soul, Andrew Sullivan (2006) invokes Thomas Hobbes's deeply skeptical, and profoundly conservative, view of the human condition:

In a world of doubt, where human beings are physical and fragile entities, you cannot know what the person next to you might do next. You might assume he is a rational, peaceful person. But he may not be. And your trust may be misplaced. In a split second, you could be injured, or stolen from, or even murdered. The starting point of a [conservative] politics therefore is the establishment of a political order that ensures your physical security as much as humanly possible. (p. 231)

A person tending toward conservatism values social order and self-regulation, Sullivan argues, because they guarantee "real peace and thereby real protection from bullies and thugs" (p. 236).

In a similar vein, Janoff-Bulman (2009) argues that political conservatism aims first and foremost to protect group members from harm. Conservatives value avoidance-based self-regulation and proscriptive moralities, which spell out how people should avoid temptations and not do those things that may harm themselves or others. They tend to adopt a prevention-focused style of motivation, privileging needs and goals that are concerned with safety, security, and avoiding losses (Molden, Lee, \& Higgins, 2008).

As conservatives are to liberals on a right-to-left political continuum, so is the broad psychological theme of self-regulation to its polar opposite, self-exploration. Self-exploration is about developing, growing, elaborating, expanding, questioning, searching, reevaluating, or discovering the self and its vicissitudes. The importance of self-exploration is central to Tomkins's $(1963,1987)$ conception of the humanistic ideological script. Humanists tend to believe that human beings are basically good, or at least not inherently bad, and therefore amenable to various programs and projects aimed at improving, even perfecting, individual human beings and humankind writ large. Whereas the normative ideological script emphasizes the social control that follows from rules and self-discipline, the humanistic script favors nurturance, empathy, and fulfilling the needs of those who are younger, weaker, or disadvantaged, so that they too will ultimately experience selffulfillment (see also Lakoff, 2002). According to Tomkins, humanists tend to celebrate human potential, even to excess, and they aim to explore, advance, and fulfill the self, while (ideally) promoting self-fulfillment in others.

In a similar vein, Janoff-Bulman (2009) argues that political liberalism aims to provide for the needs of others. Liberals value prescriptive moralities, which spell out what human beings should do in order to fulfill needs and actualize human potential. They tend to adopt a promotionfocused style of motivation, privileging needs and goals that are concerned with advancement, human growth and progress, and expanding the self (Molden et al., 2008). Less preoccupied than conservatives with internal and external threats and wary of system-justifying rationales for the status quo, liberals find great value in exploring new ideas in the world and in exploring the self.

The polarity of conservative self-regulation versus liberal self-exploration finds an especially clear articulation in Schwartz's (1992) values theory (see also Feldman, 2003). Organizing universal human values in a vast two-dimensional space, Schwartz charts a gradient running from conformity, tradition, and security on one end to self-direction and stimulation on the other. He labels the first pole conservation and its opposing end openness to change. On the conservation end, people value self-discipline, obedience, social order, family security, and other positive results of self-regulation. On the openness to change end, people value creativity, curiosity, choosing one's own goals, and other desirable states that would appear to be highly consistent with a drive to explore the self. For 
the most part, the first value cluster appears simpatico with political conservatism, whereas the second resonates with a more liberal political sensibility.

\section{The Current Study}

From the many narrative themes that might be chosen to distinguish the life stories told by politically conservative and liberal adults, the aforementioned studies and theoretical traditions in political psychology suggest that self-regulation and self-exploration would appear to be prime candidates. It is hypothesized, therefore, that American adults tending toward the conservative end of the political orientation continuum should emphasize themes of self-regulation in their narrative identities, whereas people tending toward liberalism should emphasize themes of self-exploration.

The investigation reported here draws from an in-depth empirical project that compiled extensive case studies of 128 midlife American adults, all of whom are involved in religious institutions (Christian churches) and are politically active (regularly vote and try to keep abreast of political issues). Each participant completed a set of self-report measures, including scales assessing personality traits, religious practices, political attitudes, and psychological well-being. In addition, each participant was individually interviewed for approximately two hours, during which time he or she recounted key scenes in his or her life story; described his or her religious and spiritual practices, the development of religious faith, and basic ethical beliefs and values; and answered a series of questions regarding participation in and reactions to the 2004 U. S. presidential election.

Previous analyses of selected features in the 128 case studies have begun to develop personological portraits of political conservatives and liberals in this highly religious sample of midlife American adults. McAdams et al. (2008), for example, analyzed the participants' extended descriptions of their moral belief systems for the five moral intuitions identified by Haidt (2007). In keeping with Haidt's (2007) predictions, as well as findings in Graham, Haidt, and Nosek (2009), McAdams et al. (2008) found that conservatives tended to accentuate the importance of respect for authority, loyalty to in-groups, and purity or sanctity of the self, whereas liberals tended to emphasize moral intuitions regarding fairness and harm. McAdams et al. (2008) also found mixed support for Lakoff's (2002) prediction that conservatives should feature strict-father morality in their life stories whereas liberals should feature a nurturant-caregiver morality. Analyzing the same participants' responses to a hypothetical question regarding what their lives might have been like had they not had religious faith, McAdams and Albaugh (2008) found that conservatives tended to describe a chaotic world wherein people would be unable to control their sexual and aggressive urges, marriages would fall apart, and social institutions would crumble. For politically conservative Christians in this sample, a life without God appeared to feature spectacular failures in self-regulation, presaging the lifenarrative hypothesis put forth in the current investigation. Highly religious liberals, by contrast, imagined an empty world, lacking color and texture, and devoid of the resources that make life worth living (McAdams \& Albaugh, 2008). When asked to describe their prayer practices, religious conservatives reported that they tended to pray for forgiveness and guidance in life, whereas religious liberals were more likely to pray for the provision of resources (Hanek, Olson, \& McAdams, 2011).

The current study directly examines the themes of self-regulation and self-exploration as they manifest themselves in stories of 12 important autobiographical episodes described by highly religious and politically active Christian adults living in the United States. The 12 narrated scenes may be seen as key self-defining memories in the participants' narrative identities. The analysis provides a direct test of the hypothesis that adults tending toward political conservatism should feature more themes of self-regulation in their life stories compared to adults tending toward liberalism, whereas political liberals should tend to feature themes of self-exploration more so than conservatives. The study also examines the role of the Big Five personality traits and their facets. The analysis, therefore, is able to compare self-report dispositional traits at Layer 1 in personality (such 
as conscientiousness and openness to experience) to life-narrative themes (self-regulation and self-exploration, tapping into Layer 3 in personality) in the statistical prediction of political orientation. The effects of demographic variables such as age, income, and race-ethnicity are also examined.

\section{Method}

\section{Participants and Procedure}

The participants were recruited for a project titled "Personal Faith, Politics, and the Life Story," conducted at Northwestern University's Foley Center for the Study of Lives in the years 2005 through 2007. The researchers contacted local Christian congregations to obtain participants who were between approximately 35 and 65 years of age, active members of those congregations, and willing to discuss in detail their lives, their faith, and their political views. To participate in the project, individuals also needed to have voted in the 2004 U. S. presidential election and to self-report that they were at least modestly interested in political affairs. To sample a broad range of viewpoints and demographic groups, the researchers contacted a number of different Protestant and Catholic churches, including two churches whose memberships were predominantly African American. In addition, some participants entered the project after learning about it from friends or acquaintances. In that the researchers worked with Christian congregations located mainly in Chicago and its suburbs, the project was not designed to obtain a sample fully representative of the many religious and demographic groups that populate the United States today. Instead, the project endeavored to collect intensive, high-quality data from a relatively diverse but local group of devout Christians who voted in the 2004 election and who were willing to talk in detail about important events in their lives and about the development of their beliefs.

Full case studies were assembled for 128 participants. The sample consisted of 78 women $(61 \%)$ and 50 men $(39 \%)$, ranging in age from 28 to $74(M=49.2, S D=8.5)$. A total of $64.6 \%$ of the participants reported that they were currently married; $19.7 \%$, single; $13.3 \%$, divorced; $1.6 \%$, widowed; and $0.8 \%$, cohabitating. Approximately three quarters $(75.6 \%)$ were parents. In terms of race or ethnicity, 92 were White (71.9\%); 33, African American (25.8\%); 2, Asian American (1.6\%); and 1 , Hispanic $(0.8 \%)$. The sample showed a broad range of family income but was skewed toward the upper middle class, with $43.8 \%$ of the participants reporting an annual family income of more than $\$ 100,000 ; 10.9 \%, \$ 80,000-\$ 100,000 ; 12.5 \%, \$ 60,000-\$ 80,000 ; 8.6 \%, \$ 40,000-\$ 60,000$; $16.7 \%, \$ 20,000-\$ 40,000$; and $6.3 \%$ less than $\$ 20,000$. Overall, the sample was also highly educated, with $85.9 \%$ reporting that they had obtained at least a bachelor's degree. In terms of political affiliation, slightly more than half (53.2\%) identified as Democrats, $33.1 \%$ as Republicans, $12.9 \%$ as Independents, and $0.8 \%$ as other.

\section{Political Orientation}

Political orientation was assessed directly via a 5-point self-report rating $(1=$ very liberal; $2=$ liberal $; 3=$ middle of the road, $4=$ conservative, and $5=$ very conservative). Scales of this sort are routinely used in political survey research. Jost (2006) reported that a simple rating on a bipolar liberal-conservative continuum is highly predictive of voting behavior in U. S. presidential elections.

In addition, participants completed two well-validated attitudinal scales that past research has shown tend to correlate significantly with political orientation. The first of these was the 30-item Right-Wing Authoritarianism scale (RWA: Altemeyer \& Hunsberger, 1992). In past research, scores on the RWA scale have been shown to predict a wide range of attitudes related to social, economic, and political conservatism, including political party affiliation, procapitalist attitudes, severity of jury 
sentencing decisions, harsh punishment of deviants, and opposition to such liberal policies as environmentalism, abortion rights, diversity on college campuses, and services for AIDS patients and those who are homeless (Altemeyer, 1996; Jost et al., 2003; McCann, 2008; Peterson, Doty, \& Winter, 1993). The second scale was Social Dominance Orientation (SDO: Pratto, Sidanius, Stallworth, \& Malle, 1994). This 16-item scale measures the extent to which an individual believes that dominant, high-status groups in society should continue to hold their dominance and status. SDO scale scores correlate reliably with affiliation with the Republican Party and with attitudes that are supportive of law and order, military spending, and capital punishment. SDO scale scores correlate negatively with support for women's rights, racial equality, affirmative action, gay and lesbian rights, and environmentalism (Jost et al., 2003; Sidanius \& Pratto, 1999). Jost et al. (2009) conclude that RWA typically predicts cultural conservatism and SDO predicts economic conservatism. Duckitt (2006) suggests that RWA marks responses to perceived danger from groups threatening social control, order, and stability, whereas SDO connects to perceived threats from groups activating competition and concerns about superiority.

\section{Layer 1 in Personality: Dispositional Traits}

All participants completed the Revised NEO Personality Inventory (NEO-PI-R), a 240-item self-report measure to assess the five major domains of dispositional traits (Costa \& McCrae, 1992). The Big Five trait domains are extraversion, neuroticism, agreeableness, conscientiousness, and openness to experience. For each of the five domains, the NEO-PI-R provides a summary score and scores on each of six facets in the domain. For example, the six facets for the general trait domain of conscientiousness are dutifulness, order, self-discipline, achievement striving, competence, and deliberation.

\section{Layer 3 in Personality: Life-Story Themes in Narrative Identity}

As part of a broader interview, each participant described 12 important scenes in his or her life story. Following procedures used in past research on narrative identity (e.g., McAdams, Diamond, de St. Aubin, \& Mansfield, 1997), a scene was defined as a particular episode or event in one's life that was circumscribed in time and space and that entailed an important or memorable sequence of behaviors, thoughts, and feelings. For each scene, the participant was asked to describe fully what happened in the event, who was involved, what he or she was thinking and feeling in the event, and what the scene meant, if anything, in the context of his or her entire life story. The 12 scenes were (1) a high point in life, (2) low point, (3) turning point, (4) positive childhood scene, (5) negative childhood scene, (6) vivid adolescent scene, (7) vivid adult scene, (8) imagined future scene, (9) childhood scene of faith or religion, (10) high point of religious life, (11) low point of religious life, and (12) a political scene. The inclusion of one imagined scene for the future reflected the theoretical assertion that narrative identity encompasses both the selectively reconstructed past and imagined future (McAdams, 2006).

The entire interview was transcribed, and coders worked with the typed texts of the 12 scenes. Adding up across the 12 scenes, protocol length ranged from 1,998 to 12,243 words, with a mean of 4,788. Dividing the mean by 12 yielded an average length of 399 words for any given scene.

Blind to identifying information on the participants, coders rated each transcribed narrative scene on a single, 5-point dimension of self-regulation versus self-exploration. The key question for each rating decision was this: In the narrative account of the scene, what is the protagonist's overall orientation to the self? Is the person trying to regulate the self, explore the self, or neither? Most accounts did not specify what the protagonist's overall orientation was, or they were irrelevant to the issues of self-regulation and self-exploration. These accounts received a middle score of 3 . To the 
extent the account suggested either self-regulation or self-exploration, however, the rater moved from the "set point" of 3 in one direction or the other on the 5-point continuum: $1=$ very strong self-regulation; 3 = relatively strong self-regulation; $4=$ relatively strong self-exploration; $5=$ very strong self-exploration. The account needed to provide explicit evidence of either self-regulation or self-exploration for the coder to deviate in one direction or the other from the midpoint of 3 . Unless the evidence was clear, the coder stayed at the midpoint rating. ${ }^{1}$

Self-regulation (rating of 1 or 2) was evidenced when the protagonist in the scene aims mainly to protect, preserve, maintain, monitor, control, discipline, tame, restrict, restrain, regiment, or manage the self. The protagonist works to keep the self under control, in balance, or on an even keel. Self-improvement is seen as developing better abilities or strategies to regulate the self, to refine its capacities, to maintain its strengths and good tendencies, to sublimate its powers into socially appropriate or socially beneficial actions, or to protect it from harming itself. The protagonist exerts effortful control over his or her behavior and/or thoughts. The protagonist may express caution, concern, prudence, or carefulness in the face of the self's potential flaws or unruly tendencies. The protagonist makes judicious or prudent decisions to commit or contain the self.

The following passage, taken from a woman's account of a turning-point scene (describing a period in her marriage when both she got pregnant and her husband suffered health setbacks), provides a good example of a strong self-regulation theme (score $=1)$ :

When I got pregnant with him, I had been married almost three years then and just living a wild life, partying. My husband and I just had a good time all the time, and we did not think about monetary or financial issues in a broad sense ... I stopped doing the wild things I was doing ... [making the change] helped shape me into the person that I am now, which is more responsible... The time that he [her husband] had asthma, the doctor explained how we needed to make sure we had to live in a dust-free atmosphere, and he could not be around cigarette smoke. At that time I smoked cigarettes, and I stopped that day. I'm not having another cigarette since that day, and it was 23 or 24 years ago. Yes, I stopped the day he was checked [by the doctors].

Self-exploration (rating of 4 or 5) was evidenced when the protagonist in the scene aims mainly to develop, grow, expand, question, search, examine, investigate, discover, articulate, elaborate, or fulfill the self. The protagonist is seen as open to new experiences that may stretch the self or enhance self-exploration, self-expansion, or personal growth. The protagonist seeks out new directions or different options, sometimes challenging the self, and moves forward boldly, even heedlessly, to learn more, experience more, or develop new areas or capacities of the self. Self-improvement is motivated by the desire to know, feel, or experience more. The protagonist works to develop the self's potential, to grow it, or fill it up with new things and experiences. The protagonist views the external world and the internal self as providing positive opportunities for development, growth, expansion, or reward. One favorite metaphor here is the journey or road to self-discovery, which may never reach an endpoint.

The following excerpt from a woman's account of a high-point moment in her life story illustrates a very strong self-exploration theme (score $=5$ ):

\footnotetext{
${ }^{1}$ A single, bipolar 5-point rating scale was used to assess the dimension of self-regulation versus self-exploration, rather than two independent scales (one for self-regulation and one for self-exploration), for both theoretical and empirical reasons. Theory (e.g., Janoff-Bulman, 2009; Schwartz, 1992) suggests that the two themes represent opposite motivational and value orientations. Empirically, it turns out that very few narrative responses actually show evidence of both self-regulation and self-exploration. Initial efforts operationalized both themes as independent (3-point) scales, but resultant scores on the two were so highly negatively correlated as to provide redundant information. Therefore, it was decided to collapse the two into one, bipolar, 5-point rating scale.
} 
... there's that little bit of reflectiveness that you get with an empty nest. I would say it has truly been a highlight to get shaken up ... The decision to leave and the excitement of starting something really fresh caused me to have to look at all of the things I valued and really do a lot of personal reflection... I think I really focused back onto what are important things for me ... So I really want to experiment with some of the areas I want to grow into and not just do something because I've done it that way before.

For each participant, the 12 ratings (one for each scene) were summed and averaged, providing a final total score, ranging hypothetically between 1.0 and 5.0. Intercoder reliability was +.87 , calculated as the intraclass correlation between two independent coders' respective total (averaged) scores obtained for each of the first 50 participants in the study.

\section{Results}

Table 1 provides the descriptive statistics for the main variables in the study. The mean score on the liberalism-conservatism self-rating (2.94) approached the midpoint $(3=$ middle of the road $)$ of the scale. A total of $11 \%$ of the participants identified themselves as very liberal (a self-rating of 1); $26 \%$ as liberal; $26.8 \%$ middle of the road; $29.9 \%$ conservative; and $6.3 \%$ very conservative (a self-rating of 5). Self-ratings on political orientation were strongly associated with RWA, $r(126)=.60, p<.001$, and less strongly but still significantly associated with SDO, $r(125)=.32$, $p<.001$. Therefore, participants who rated themselves toward the conservative end of the 5-point self-rating continuum also tended to score high on right-wing authoritarianism and on social dominance orientation. RWA and SDO were also significantly associated with each other, although at a modest level, $r(125)=.22, p<.05$. Given these significant intercorrelations, we also calculated a composite political orientation index, which was the sum of the standard scores of RWA, SDO, and the liberalism-conservatism self-rating.

Among the Big Five dispositional traits, several significant intercorrelations were observed. Neuroticism correlated negatively with extraversion $(r=-.20, p<.05)$, agreeableness $(r=-.40$, $p<.001)$, and conscientiousness $(r=-.42, p<.001)$; extraversion correlated positively with openness to experience $(r=.41, p<.001)$; and agreeableness and conscientiousness were positively associated with each other $(r=.23, p<.01)$. Women scored significantly higher than men on agreeableness $\left(M_{\text {women }}=134.45, S D=13.86\right.$, and $\left.M_{\text {men }}=128.36, S D=13.99\right), t(126)=2.42, p<.05$. African American participants scored significantly higher than Whites on right-wing authoritarianism $\left(M_{\text {African American }}=169.23, S D=27.93\right.$, and $\left.M_{\text {White }}=126.07, S D=34.42\right), t(123)=6.47, p<.001$. White participants, however, scored significantly higher on social dominance orientation $\left(M_{\text {White }}=34.51, S D=13.38\right.$, and $\left.M_{\text {African American }}=27.47, S D=10.34\right), t(122)=2.71, p<.05$. Compared to African Americans, White participants also scored significantly higher (toward the selfexploration end) on the life-narrative index $\left(M_{\text {White }}=3.07, S D=0.37\right.$, and $M_{\text {African American }}=2.71$, $S D=0.26), t(123)=5.03, p<.001$. Education was positively correlated with openness to experience $(r=.27, p<.01)$. Age was negatively associated with neuroticism $(r=-.27, p<.01)$ and positively associated with both agreeableness $(r=.22, p<.05)$ and conscientiousness $(r=.19, p<.05)$.

Table 2 shows correlations between the self-report variables for political orientation and personality traits on the one hand and the narrative index of self-regulation versus self-exploration on the other. Consistent with the study's main hypothesis, political conservatism (assessed on the self-report liberal-conservative continuum, RWA, SDO, and the composite) was strongly and significantly associated with constructing autobiographical scenes that emphasized self-regulation over self-exploration. The strongest correlation was with RWA. The narrative index also showed significant associations with certain trait dimensions and their facets. Self-exploration (scoring higher on the self-regulation versus self-exploration index) was positively associated with the trait of openness 
Table 1. Descriptive Statistics for Main Variables

\begin{tabular}{|c|c|c|c|}
\hline & $M$ & $S D$ & Range \\
\hline \multicolumn{4}{|l|}{ Political orientation } \\
\hline Liberalism-conservatism self-rating & 2.94 & 1.12 & $1-5$ \\
\hline Right-wing authoritarianism (RWA) & 136.98 & 37.78 & $57-216$ \\
\hline Social dominance orientation (SDO) & 32.70 & 12.85 & $16-75$ \\
\hline \multicolumn{4}{|l|}{ Personality traits } \\
\hline Neuroticism & 78.72 & 20.52 & $10-123$ \\
\hline Anxiety & 14.39 & 5.35 & $0-27$ \\
\hline Angry hostility & 11.77 & 4.56 & $1-25$ \\
\hline Depression & 12.53 & 5.07 & $0-25$ \\
\hline Self-consciousness & 14.02 & 4.51 & $0-24$ \\
\hline Impulsiveness & 16.53 & 4.63 & $5-26$ \\
\hline Vulnerability & 9.48 & 3.30 & $0-17$ \\
\hline Extraversion & 119.03 & 17.30 & $67-171$ \\
\hline Warmth & 24.52 & 3.41 & $15-32$ \\
\hline Gregariousness & 18.63 & 5.16 & $1-30$ \\
\hline Assertiveness & 18.70 & 4.58 & $6-31$ \\
\hline Activity & 19.69 & 4.34 & $9-31$ \\
\hline Excitement seeking & 15.35 & 5.05 & $3-25$ \\
\hline Positive emotions & 22.15 & 4.66 & $4-32$ \\
\hline Openness to experience & 120.72 & 16.79 & $76-169$ \\
\hline Fantasy & 18.55 & 4.72 & $8-31$ \\
\hline Aesthetics & 20.69 & 4.46 & $6-32$ \\
\hline Feelings & 22.38 & 3.34 & $9-31$ \\
\hline Actions & 17.52 & 4.30 & $7-28$ \\
\hline Ideas & 21.51 & 4.67 & $9-32$ \\
\hline Values & 20.07 & 4.60 & $9-29$ \\
\hline Agreeableness & 132.07 & 14.17 & $92-178$ \\
\hline Trust & 21.95 & 3.93 & $9-31$ \\
\hline Straightforwardness & 22.55 & 4.07 & $11-32$ \\
\hline Altruism & 24.88 & 2.89 & $16-32$ \\
\hline Compliance & 19.60 & 4.05 & $9-31$ \\
\hline Modesty & 20.13 & 3.95 & $8-30$ \\
\hline Tender-mindedness & 22.95 & 3.32 & $13-32$ \\
\hline Conscientiousness & 123.71 & 19.31 & $68-174$ \\
\hline Competence & 23.76 & 3.15 & $13-31$ \\
\hline Order & 18.16 & 4.89 & $4-30$ \\
\hline Dutifulness & 22.84 & 4.22 & $11-32$ \\
\hline Achievement striving & 20.23 & 4.79 & $8-31$ \\
\hline Self-discipline & 20.81 & 4.42 & $9-32$ \\
\hline Deliberation & 17.91 & 4.31 & $4-27$ \\
\hline \multicolumn{4}{|l|}{ Life-narrative theme } \\
\hline Self-regulation vs. self-exploration & 2.96 & 1.12 & $1-5$ \\
\hline
\end{tabular}

to experience (and with four of its six facets) and with agreeableness (and with two of its six facets). The narrative index showed no significant associations with extraversion, neuroticism, or conscientiousness, except for a negative association with the extraversion facet of excitement seeking.

Consistent with past studies, the trait of openness to experience was negatively associated with political conservatism: $r=-.37, p<.001$ for the self-rating; $r=-.48, p<.001$ for RWA; $r=-.26$, 
Table 2. Correlations of Political Orientation and Traits with the Narrative Theme of Self-Regulation versus Self-Exploration

\begin{tabular}{|c|c|}
\hline \multicolumn{2}{|l|}{ Political orientation } \\
\hline Liberalism-conservatism self-rating ${ }^{1}$ & $-.39 * * *$ \\
\hline Right-wing authoritarianism (RWA) & $-.60 * * *$ \\
\hline Social dominance orientation (SDO) & $-.24 * *$ \\
\hline Composite $^{2}$ & $-.53 * * *$ \\
\hline \multicolumn{2}{|l|}{ Personality traits } \\
\hline Neuroticism & .04 \\
\hline Anxiety & .17 \\
\hline Angry hostility & -.08 \\
\hline Depression & .05 \\
\hline Self-consciousness & .00 \\
\hline Impulsiveness & .00 \\
\hline Vulnerability & -.02 \\
\hline Extraversion & -.03 \\
\hline Warmth & .14 \\
\hline Gregariousness & -.01 \\
\hline Assertiveness & -.01 \\
\hline Activity & .12 \\
\hline Excitement seeking & $-.26 * *$ \\
\hline Positive emotions & -.02 \\
\hline Openness to experience & $.32 * *$ \\
\hline Fantasy & $.19^{*}$ \\
\hline Aesthetics & .05 \\
\hline Feelings & $.27 * *$ \\
\hline Actions & .06 \\
\hline Ideas & $.19 *$ \\
\hline Values & $.49 * * *$ \\
\hline Agreeableness & $.19 *$ \\
\hline Trust & $.31 * * *$ \\
\hline Straightforwardness & .03 \\
\hline Altruism & .16 \\
\hline Compliance & .03 \\
\hline Modesty & .03 \\
\hline Tender-mindedness & $.18^{*}$ \\
\hline Conscientiousness & .05 \\
\hline Competence & .13 \\
\hline Order & -.03 \\
\hline Dutifulness & .15 \\
\hline Achievement striving & -.02 \\
\hline Self-discipline & .02 \\
\hline Deliberation & .02 \\
\hline
\end{tabular}

Note: Positive correlations indicate that higher scores on the variable are associated with self-exploration, and negative correlations indicate that higher scores on the variable are associated with self-regulation.

${ }^{1}$ Ratings of 1 =very liberal; 2 = liberal; 3 = middle of the road; $4=$ conservative $;=$ very conservative.

${ }^{2}$ Political orientation composite equals the sum of standardized scores for the 5-point liberal-conservative self-rating, RWA, and SDO. 
Table 3. Hierarchical Regression Results for Political Composite

\begin{tabular}{|c|c|c|c|c|c|}
\hline Model & Predictor & $\beta$ & $R$ & $R^{2}$ & $\Delta R^{2}$ \\
\hline \multirow[t]{4}{*}{1} & & & .357 & .128 & $.128 * * *$ \\
\hline & Age & -.056 & & & \\
\hline & Race & -.071 & & & \\
\hline & Social class & $-.380 * * *$ & & & \\
\hline \multirow[t]{9}{*}{2} & & & .574 & .329 & $.202 * * *$ \\
\hline & Age & -.016 & & & \\
\hline & Race & -.116 & & & \\
\hline & Social class & $-.308 * *$ & & & \\
\hline & Openness & $-.421 * * *$ & & & \\
\hline & Conscientiousness & .122 & & & \\
\hline & Extraversion & .123 & & & \\
\hline & Agreeableness & $-.175^{*}$ & & & \\
\hline & Neuroticism & -.042 & & & \\
\hline \multirow[t]{10}{*}{3} & & & .666 & .444 & $.115^{* * *}$ \\
\hline & Age & -.023 & & & \\
\hline & Race & $-.197 *$ & & & \\
\hline & Social class & -.182 & & & \\
\hline & Openness & $-.332 * * *$ & & & \\
\hline & Conscientiousness & .147 & & & \\
\hline & Extraversion & .055 & & & \\
\hline & Agreeableness & -.110 & & & \\
\hline & Neuroticism & -.010 & & & \\
\hline & Narrative theme $e^{1}$ & $-.415^{* * *}$ & & & \\
\hline
\end{tabular}

\footnotetext{
${ }^{1}$ Self-regulation versus self-exploration in autobiographical scenes. Higher scores indicate more self-exploration; lower scores indicate more self-regulation. In this analysis, higher scores were associated with liberalism on the composite, and lower scores with conservatism.

$* p<.05 ; * * p<.01 ; * * * p<.001$.
}

$p<.01$ for SDO; and $r=-.50, p<.001$ for the composite. The trait of agreeableness was negatively associated with SDO $(r=-.25, p<.01)$ and with the composite $(r=-.18, p<.05)$.

Multiple regression was employed to assess the relative strength of demographic factors (age, race, and social class), personality traits (the Big Five factors), and the narrative theme of selfregulation versus self-exploration in the statistical prediction of political orientation. Using the composite index for political orientation as the dependent variable, we entered three successive blocks of variables into a hierarchical regression to test, respectively, the effects of (1) demographics, (2) dispositional traits (Layer 1 in personality), and (3) the life-narrative theme of self-regulation versus self-exploration (Layer 3 in personality). Model 1 employed the demographic variables of age, social class (sum of standardized scores on education and income), and race (White or African American), entered as a dummy. Model 2 employed demographics plus traits (openness, conscientiousness, extraversion, agreeableness, and neuroticism). Model 3 employed demographics plus traits plus the narrative theme of self-regulation versus self-exploration. The same hierarchical regression procedure using the three models was repeated three times, once for each of the three individual political orientation variables: the liberalism-conservatism self-rating, RWA, and SDO.

Table 3 presents the main findings from the first regression procedure, employing the political composite as the dependent variable. Demographics accounted for a statistically significant amount of the variance in composite political orientation, $R^{2}=.13, F(3,119)=5.80, p<.01$. Social class proved to be the statistically significant predictor, $\beta=-.380, p<.01$. Participants with lower social-class standing (lower education and lower income) were more conservative on the political 
composite (conservative self-rating, higher RWA, and higher SDO). Age and race were unrelated to the political composite. Adding the five traits in Model 2 made for a significant increase in variance accounted for, $R^{2}=.33, \Delta R^{2}=.20, F(5,114)=6.86, p<.001$. Openness showed a very strong effect, with high scores on openness predicting liberalism, $\beta=-.428, p<.001$. Agreeableness also showed a statistically significant effect, with high agreeableness predicting more liberal scores on the political composite, $\beta=-.175, p<.05$.

Most importantly, when both demographics and dispositional traits (Layer 1 in personality) were accounted for, the narrative theme of self-regulation versus self-exploration (Layer 3 in personality) explained unique variance in the composite political orientation variable, $R^{2}=.44, \Delta R^{2}=.12$, $F(1,113)=23.28, p<.001$. In the full Model 3 , race $(\beta=-.197, p<.05)$ replaced social class $(\beta=-.182, p=.059)$ as a significant predictor of conservatism; openness $(\beta=-.332, p<.001)$ but not agreeableness $(\beta=-.110, p=.175)$ proved to be the strong trait predictor; and the narrative variable showed a robust $(\beta=-.415, p<.001)$ effect. With all the relevant variables in the equation, then, political conservatism (as indexed on the composite) was significantly associated with being African American, scoring low on the trait of openness to experience, and narrating life-story scenes of self-regulation. By contrast, liberals tended to be White and high in openness, and they tended to narrate life story scenes of self-exploration. The trait of openness and the narrative variable showed especially strong effects, whereas the effect of race (which emerged as significant only in Model 3 of the regression analysis) was of relatively modest magnitude.

The effect of race in the first regression analysis reflects the fact that African American participants in the current sample scored significantly higher than White participants on right-wing authoritarianism. Correspondingly, the full regression analysis for RWA showed that both race (being African American) and lower social class (lower education and lower income) were significant predictors of right-wing authoritarianism, along with strong effects again for low openness and the narrative theme of self-regulation. By contrast, the full regression analysis for the self-rating of liberal-conservative showed no race or social-class effects. Rating oneself toward the conservative end was strongly associated with low trait openness and the narrative theme of self-regulation only. The regression analysis for SDO showed a different pattern. In the full Model 3, SDO was significantly associated with being White (as opposed to African American) and with lower social class. Whereas the narrative theme of self-regulation was significantly associated with SDO, trait openness was not related. Instead, trait agreeableness showed a very strong negative and significant association with SDO, and trait conscientiousness showed a significant positive association with SDO. Table 4 summarizes results from the full (Model 3) regression analyses for the self-rating of liberalismconservatism, RWA, and SDO.

When all four of the regression analyses are taken into consideration, four general conclusions regarding the overall findings emerge. First, the narrative theme of self-regulation versus selfexploration showed strong associations with political conservatism, across the board. Whether measured via a self-rating, RWA, SDO, or the composite, political conservatives tended to narrate their life stories with a strong emphasis on self-regulation, whereas political liberals emphasized self-exploration in their narrative accounts. Even when the demographic and trait variables were statistically accounted for, the narrative theme significantly explained unique variance in political orientation. Second, the trait of openness to experience proved a strong and significant predictor of conservatism in three of the four analyses, failing to show a significant association with SDO only. Third, the other traits in the Big Five scheme showed little effect, except for a notably strong negative association between trait agreeableness and SDO and a modest but significant association between conscientiousness and SDO. Fourth, demographics mattered, though in different ways. Whereas African Americans and participants with less education and lower incomes tended to score significantly higher on RWA (one index of conservatism), White participants (as well as participants lower in social class) tended to score higher on SDO (another index of conservatism). The subsidiary 
Table 4. Summary of Regression Analyses for Self-Rating of Liberalism-Conservatism, RWA, and SDO

\begin{tabular}{|c|c|c|c|}
\hline \multicolumn{4}{|c|}{ For Self-Rating of Conservatism } \\
\hline Predictor & $\beta$ & $R$ & $R^{2}$ \\
\hline$\left(\right.$ Model 3) ${ }^{1}$ & & .506 & .256 \\
\hline Age & -.131 & & \\
\hline Race & -.172 & & \\
\hline Social class & .034 & & \\
\hline Openness & $-.265 * *$ & & \\
\hline Conscientiousness & .086 & & \\
\hline Extraversion & .029 & & \\
\hline Agreeableness & -.030 & & \\
\hline Neuroticism & -.008 & & \\
\hline Narrative theme ${ }^{2}$ & $-.377 * * *$ & & \\
\hline \multicolumn{4}{|l|}{ For RWA } \\
\hline Predictor & $\beta$ & $R$ & $R^{2}$ \\
\hline (Model 3) & & .752 & .565 \\
\hline Age & .002 & & \\
\hline Race & $.202 *$ & & \\
\hline Social class & $-.188^{*}$ & & \\
\hline Openness & $-.323 * * *$ & & \\
\hline Conscientiousness & .114 & & \\
\hline Extraversion & .071 & & \\
\hline Agreeableness & .109 & & \\
\hline Neuroticism & .088 & & \\
\hline Narrative theme & $-.356 * * *$ & & \\
\hline \multicolumn{4}{|l|}{ For SDO } \\
\hline Predictor & $\beta$ & $R$ & $R^{2}$ \\
\hline (Model 3) & & .600 & .360 \\
\hline Age & .087 & & \\
\hline Race & $-.512 * * *$ & & \\
\hline Social class & $-.256^{*}$ & & \\
\hline Openness & -.139 & & \\
\hline Conscientiousness & $.173^{*}$ & & \\
\hline Extraversion & .051 & & \\
\hline Agreeableness & $-.350 * * *$ & & \\
\hline Neuroticism & -.165 & & \\
\hline Narrative theme & $-.255^{*}$ & & \\
\hline
\end{tabular}

${ }^{1}$ Model 3 refers to the full regression model, the last step of the hierarchical regression analysis, wherein demographics, traits, and the narrative theme are all entered simultaneously as predictors of the dependent variable.

${ }^{2}$ Self-regulation vs. self-exploration in autobiographical scenes. Higher scores indicate more self-exploration; lower scores indicate more self-regulation. In these analyses, higher scores were negatively associated with all three dependent variables. In other words, self-regulation predicted self-reported conservatism, RWA, and SDO.

$* p<.05 ; * * p<.01 ; * * * p<.001$. 
analyses with RWA and SDO, therefore, show that political orientation (conservatism) is a complex construct that may be apprehended somewhat differently as a function of race and social class. Interestingly, these differences seemed to cancel each other out for the overall self-rating of conservatism. The simple, one-item self-rating for liberalism-conservatism showed no associations with race or social class.

\section{Discussion}

The findings from the 128 case studies of religious and politically active midlife American adults show clearly that the life-story theme of self-regulation versus self-exploration in narrative identity is strongly and consistently associated with political orientation. Whereas demographics and dispositional traits were also significantly associated with political orientation, the life-narrative theme of self-regulation versus self-exploration accounted for unique variance in self-report indices of political conservatism and liberalism.

Adults leaning toward political conservatism tended to narrate the most important scenes in their life stories (narrative identities) with a strong emphasis on self-regulation. Whether assessed by a self-report rating of political orientation, right-wing authoritarianism, social dominance orientation, or a composite of the three, political conservatism was strongly associated with describing efforts in life to control, discipline, monitor, restrain, restrict, or manage the self. By contrast, American adults leaning toward political liberalism tended to narrate the most important scenes in their life stories with a strong emphasis on self-exploration. They described pivotal, self-defining scenes in their lives wherein they sought to develop, grow, expand, elaborate, or fulfill the self. Consistent with past research, furthermore, the trait of openness to experience proved to be a significant predictor of political orientation, though it failed to reach statistical significance in the regression analysis for SDO (wherein the trait of agreeableness accounted for a good deal of the variance). Also consistent with past studies, African Americans tended to score higher than Whites on RWA, with the reverse occurring for SDO. Lower social class was associated with both RWA and SDO, but in neither case did demographic variables trump the personality variables of traits and stories.

Let us briefly consider two case examples to illustrate the contrast in narrative identity between self-regulation and self-exploration.

Jason Koepke is a White, 35-year-old marketing consultant, married with no children, who identifies as an evangelical Christian. He scores relatively high on both right-wing authoritarianism and social dominance orientation, and he describes himself as a political conservative. He voted for George W. Bush in both the 2000 and 2004 U. S. presidential elections. He admires Bush's steadfast resolve and his commitment to Christian principles. Jason's life-story interview contains many instances when he struggled to control his impulses and regulate his behavior in the face of temptations. In eighth grade, he is overjoyed to receive an invitation to a party hosted by the most popular kids in class. But when he arrives at the party, he finds that most of his would-be friends are drinking alcohol or taking drugs. He feels a strong urge to join in so that he can be accepted as one of the "cool" kids in school, but he ultimately resists (and is rejected by his peers). When asked to describe the worst moment in his own life, Jason tells how his wife caught him downloading pornography five years ago. He says: "This was quite a revelation to her because she really had no idea that I had been addicted to pornography my whole life and had this secret life, and so like this secret that I had kind of carried and cultivated and felt a lot of guilt and shame about in a moment was completely opened." Subsequently, Jason enlisted in a Christian "recovery program," designed to give him insight into his struggles with sexuality and help him regulate his sexual and emotional life. Five years later, he feels more control and discipline in his life, and he reports that his marriage is very happy as a result. Jason is deeply involved in church activities and is an active participant in local charities. 
Robert Sundquist is a White, 67-year-old businessman, married with three grown children. With respect to religion, he identifies as an "independent Protestant." With respect to politics, he is a moderately liberal Democrat, who voted for Al Gore in the 2000 U. S. presidential election and John Kerry in 2004. He says he despises the religious right wing in American politics and argues that extreme conservatism is a reaction against the threats and anxieties of modern life. Throughout his life-story interview, Robert extols the values of education, critical inquiry, and self-examination. Key moments in the story typically involve learning something new about himself or other people. His life-story high point was experiencing an epiphany about his own identity as he walked across his college campus as a freshman. His low point was a cancer diagnosis four years ago. He felt "cheated and depressed," and he worried that he might die. Through the recovery process, however, Robert ended up exploring new ideas about himself and his relationships with the people he loves. For him, cancer stimulated self-exploration. Robert looks forward to retirement as providing more opportunity for traveling and learning. Like Jason, Robert is active in his church, and he gives time and money to local charities.

The robust findings regarding the life-narrative themes of self-regulation and self-exploration are consistent with Tomkins's (1987) theory of ideological scripts. According to Tomkins, political conservatives tend to see their lives and the world in terms of a normative script, wherein strict norms and regulatory processes must consistently be applied in order to reign in unruly human impulses. By contrast, liberals adopt a humanistic script, valuing self-exploration, expansion, and the fulfillment of human needs. The findings are also consistent with Janoff-Bulman's (2009) argument that conservatives generally adopt a prevention-focus approach toward life, seeking to protect the self and others, whereas liberals adopt a promotion-focus approach in order to provide for the self and others. In a very broad sense, conservatives may be more concerned about preventing harm in the face of threats, especially harm that arises from failures in self-regulation, whereas liberals may be more concerned with promoting the well-being of self and others in the face of perceived opportunities in the environment. In terms of Schwartz's (1992) value theory, the life stories of political conservatives tend to prioritize the security and conformity that result from self-regulation whereas the life stories of liberals tend to accentuate exploration, creativity, and openness to change.

The life-narrative findings contribute a new piece to the literature on personality and political orientation. Whereas past studies have mainly linked political orientation to dispositional traits like openness and conscientiousness (Layer 1 in personality) and goals and motives (Layer 2), the current study suggests that the themes that animate a person's narrative identity - the internalized and evolving story of the self through which a person defines who I am, how I came to be, and where my life may be going (Layer 3 in personality) — have a strong association with political orientation, an association that cannot be explained by personality traits. Whereas dispositional traits may account for phenotypic consistencies in behavior across situations and over time, life narratives tap into the more dynamic and contingent features of psychological individuality that speak directly to how people make meaning in the world. Traits (Layer 1) and stories (Layer 3), therefore, may provide complementary perspectives on personality, and both appear to be deeply implicated in political orientation. Future studies should examine, moreover, how traits and stories combine with Layer-2 constructs in personality, like motives and goals, in the prediction of political orientation and political behavior.

The findings regarding self-regulation versus self-exploration leave open the question of the ultimate origins of these life-narrative themes. Do conservatives and liberals tell different stories about their lives because they have experienced dramatically different life events in the first place? According to this first possibility, conservatives may have a richer repertoire of past experiences entailing impulse control and self-discipline, compared to liberals, and they may more often struggle with, or at least think about, self-regulation in everyday life. Similarly, liberals may have more past experiences of self-exploration to call upon, compared to conservatives, and they may 
even have been strongly encouraged to question and expand the self as children. A second, alternative possibility is that conservatives and liberals may not differ so much on the objective details of their life histories as they do on the meanings or narrative interpretations they make of their histories. According to this second line of thinking, conservatives and liberals interpret the past in different ways, even when considering similar life events. Life-narrative studies like this one are not typically equipped-methodologically or epistemologically-to tease apart these two possibilities. Many researchers engaged in life-narrative research acknowledge that both are likely true-life stores are both discovered and made, based on both lived reality and the idiosyncratic interpretations that people make of reality once it has been lived (Hammack, 2008; McAdams et al., 1997; Singer, 2005).

By way of further limitations, the findings regarding themes of self-regulation and selfexploration in the current study are based on a highly select, nonrepresentative sample of midlife American adults who profess a strong religious affiliation with Christianity. Religion and politics are tied together in American society today in ways that may be remarkably different from what prevails in other democratic societies (Wills, 2007). American voters are tuned into the religious sensibilities of their political candidates to a much greater extent than is currently the case in Western Europe, for example, and religious movements and sentiments have played central roles in American political history for over two centuries, from the abolition of slavery in the 1860 s to prohibition, civil rights, and the anti-abortion movement in the twentieth century. The findings from the current study, therefore, must be seen in their unique cultural and historical context. The 128 case studies chosen for this analysis may, accordingly, contain certain peculiarities, calling into question the extent to which the results may generalize to other samples. For example, it may be the case that the narrative theme of self-regulation has particular resonance for highly religious people, given that religions nearly always set forth rules and principles regarding impulse control, social conformity, and responsible human conduct. This may be apparent, for example, in the brief case example of Jason, presented above. A less religious sample might show less variance on the thematic measure employed in the current study, or the mean scores might be more skewed to the self-exploration end.

Furthermore, the self-report ratings of political conservatism and liberalism reflect how these concepts are understood by American adults today. The terms "conservative" and "liberal" mean different things in different societies, and indeed their meanings in American society have changed substantially over past decades (Allitt, 2009; McAdams, 2011). Whether the findings from the current study may be directly applicable to other religious groups, other age groups, and other national groups, therefore, remains an open empirical question. Nonetheless, the fact that conceptual linkages of self-regulation to political conservatism and self-exploration to political liberalism may be found in many different theoretical perspectives, from Tomkins's $(1963,1987)$ script theory to Janoff-Bulman's (2009) arguments concerning prevention and promotion, lends credibility to the supposition that the current findings might have relevance for other samples and settings.

In conclusion, the current study opens up a new way to think about how personality and politics may come together in individual adult lives. Despite the limitations, the intensive life-narrative data collected and analyzed for this report suggest that political orientation may be linked to individual lives in ways that go well beyond what most researchers typically observe, reliant as behavioral scientists typically are on attitudinal surveys, self-report scales, voting records, and the like. The study shows that, along with important demographic variables, dispositional traits (Layer 1 in personality) and narrative identity (Layer 3 in personality) complement each other in accounting for individual differences in political orientation. The intensive examination of the stories people live by can shed new light on the psychology of political orientation while also offering new methods for theory development and hypothesis testing. 


\section{ACKNOWLEDGMENTS}

The research was supported by a grant to the first author from the Foley Family Foundation to establish the Foley Center for the Study of Lives at Northwestern University. The authors would like to thank the following people at the Foley Center who provided assistance on data collection, coding, and analysis: Michelle Albaugh, Keith Cox, Emily Farber, Jennifer Daniels, Miriam Klevan, Gina Logan, Katie Magrino, Brad Olson, Katie White, and Raelle Wilson. Correspondence should be addressed to Dan P. McAdams, Department of Psychology, Northwestern University, 2120 Campus Drive, Evanston, IL 60208; dmca@ northwestern.edu

\section{REFERENCES}

Adorno, T. W., Frenkel-Brunswik, E., Levinson, D. J., \& Sanford, R. N. (1950). The authoritarian personality. New York: Harper and Row.

Allitt, P. (2009). The conservatives: Ideas and personalities throughout American history. New Haven, CT: Yale University Press.

Altemeyer, R. A. (1996). The authoritarian specter. Cambridge, MA: Harvard University Press.

Altemeyer, R. A., \& Hunsberger, B. E. (1992). Authoritarianism, religious fundamentalism, quest, and prejudice. International Journal for the Psychology of Religion, 2, 113-133.

Arnett, J. J. (2000). Emerging adulthood: A theory of development from the late teens through the twenties. American Psychologist, 55, 469-480.

Bem, D. J. (1970). Beliefs, attitudes, and human affairs. Belmont, CA: Brooks/Cole.

Carney, D. R., Jost, J. T., Gosling, S. D., \& Potter, J. (2008). The secret lives of liberals and conservatives: Personality profiles, interaction styles, and the things they leave behind. Political Psychology, 29, 807-840.

Costa, P. T., Jr., \& McCrae, R. R. (1992). The NEO-PI-R: Professional manual. Odessa, FL: Psychological Assessment Resources.

Duckitt, J. (2006). Differential effects of right wing authoritarianism and social dominance orientation on outgroup attitudes and their mediation by threat from competitiveness of outgroups. Personality and Social Psychology Bulletin, 32, 684-696.

Emmons, R. A. (1999). The psychology of ultimate concerns: Motivation and spirituality in personality. New York: Guilford Press.

Erikson, E. H. (1968). Identity: Youth and crisis. New York: Norton.

Feldman, S. (2003). Values, ideology, and the structure of political attitudes. In D. Sears, L. Huddy, \& R. Jervis (Eds.), Oxford handbook of political psychology (pp. 477-508). New York: Oxford University Press.

Fromm, E. (1947). Man for himself: An inquiry into the psychology of ethics. New York: Holt, Rinehart, and Winston.

Graham, J., Haidt, J., \& Nosek, B. A. (2009). Liberals and conservatives rely on different sets of moral foundations. Journal of Personality and Social Psychology, 96, 1029-1046.

Haidt, J. (2007, May 18). The new synthesis in moral psychology. Science, 316, 998-1001.

Hammack, P. L. (2008). Narrative and the cultural psychology of identity. Personality and Social Psychology Review, 12, 222-247.

Hanek, K. J., Olson, B., \& McAdams, D. P. (2011). Political orientation and the psychology of Christian prayer: How conservatives and liberals pray. International Journal for the Psychology of Religion, 21, 30-42.

Hirsh, J. B., DeYoung, C. G., Xu, X., \& Peterson, J. B. (2010). Compassionate liberals and polite conservatives: Associations of agreeableness with political ideology and moral values. Personality and Social Psychology Bulletin, 36, 655-664.

Janoff-Bulman, R. (2009). To provide or protect: Motivational bases of political liberalism and conservatism. Psychological Inquiry, 20, 120-128.

Jost, J. T. (2006). The end of the end of ideology. American Psychologist, 61, 651-670.

Jost, J. T., Federico, C. M., \& Napier, J. L. (2009). Political ideology: Its structure, functions, and elective affinities. In S. Fiske, D. Schacter, \& R. Sternberg (Eds.), Annual review of psychology (vol. 60, pp. 307-337). Palo Alto, CA: Annual Reviews, Inc.

Jost, J. T., Glaser, J., Kruglanski, A. W., \& Sulloway, F. J. (2003). Political conservatism as motivated social cognition. Psychological Bulletin, 129, 339-375.

Lakoff, G. (2002). Moral politics: How liberals and conservatives think (2nd ed.). Chicago: University of Chicago Press. 
McAdams, D. P. (1985). Power, intimacy, and the life story: Personological inquiries into identity. New York: Guilford Press.

McAdams, D. P. (1996). Personality, modernity, and the storied self: A contemporary framework for studying persons. Psychological Inquiry, 7, 295-321.

McAdams, D. P. (2006). The redemptive self: Stories Americans live by. New York: Oxford University Press.

McAdams, D. P. (2008). Personal narratives and the life story. In O. P. John, R. A. Robins, \& L. Pervin (Eds.), Handbook of personality: Theory and research (3rd ed., pp. 241-261). New York: Guilford Press.

McAdams, D. P. (2011). George W. Bush and the redemptive dream: A psychological portrait. New York: Oxford University Press.

McAdams, D. P., \& Albaugh, M. (2008). What if there were no God? Politically conservative and liberal Christians imagine their lives without faith. Journal of Research in Personality, 42, 1668-1672.

McAdams, D. P., Albaugh, M., Farber, E., Daniels, J., Logan, R. L., \& Olson, B. (2008). Family metaphors and moral intuitions: How conservatives and liberals narrate their lives. Journal of Personality and Social Psychology, 95, 978-990.

McAdams, D. P., Diamond, A., de St. Aubin, E., \& Mansfield, E. D. (1997). Stories of commitment: The psychosocial construction of generative lives. Journal of Personality and Social Psychology, 72, 678-694.

McAdams, D. P., \& Olson, B. (2010). Personality development: Continuity and change. In S. Fiske, D. Schacter, \& R. Sterberg (Eds.), Annual review of psychology (vol. 61, pp. 517-542). Palo Alto, CA: Annual Reviews, Inc.

McAdams, D. P., \& Pals, J. L. (2006). A new Big Five: Fundamental principles for an integrative science of personality. American Psychologist, 61, 204-217.

McAdams, D. P., \& Walden, K. (2010). Jack Block, the Big Five, and personality from the standpoint of the actor, agent, and author. Psychological Inquiry, 21, 50-56.

McCann, S. J. H. (2008). Societal threat, authoritarianism, conservatism, and U. S. state death sentencing (1977-2004). Journal of Personality and Social Psychology, 94, 913-923.

McLean, K. C. (2008). The emergence of narrative identity. Social and Personality Psychology Compass, 2/4, $1685-1702$.

McLean, K. C., Pasupathi, M., \& Pals, J. L. (2007). Selves creating stories creating selves: A process model of selfdevelopment. Personality and Social Psychology Review, 11, 262-278.

Molden, D. C., Lee, A. Y., \& Higgins, E. T. (2008). Motivations for promotion and prevention. In J. Shah \& W. Gardner (Eds.), Handbook of motivation science (pp. 169-187). New York: Guilford Press.

Mroczek, D. K., \& Little, T. (Eds.). (2006). The handbook of personality development. Mahwah, NJ: Lawrence Erlbaum.

Oesterreich, D. (2005). Flight into security: A new approach and measure of the authoritarian personality. Political Psychology, 26, 275-297.

Peterson, B. E., Doty, R. M., \& Winter, D. G. (1993). Authoritarianism and attitudes towards contemporary social issues. Personality and Social Psychology Bulletin, 19, 174-184.

Pratto, F., Sidanius, J., Stallworth, L. M., \& Malle, B. G. (1994). Social dominance orientation: A personality variable predicting social and political attitudes. Journal of Personality and Social Psychology, 67, 741-763.

Schwartz, S. H. (1992). Universals in content and structure of values: Theoretical advances and empirical tests in 20 countries. In M. Zanna (Ed.), Advances in experimental social psychology (vol. 25, pp. 1-65). New York: Academic Press.

Sheldon, K. M., Cheng, C., \& Hilpert, J. (2011). Understanding well-being and optimal human functioning: Applying the multilevel personality in context (MPIC) model. Psychological Inquiry, 22, 1-16.

Sidanius, J., \& Pratto, F. (1999). Social dominance: An intergroup theory of social hierarchy and oppression. New York: Cambridge University Press.

Singer, J. A. (2005). Personality and psychotherapy: Treating the whole person. New York: Guilford Press.

Sullivan, A. (2006). The conservative soul. New York: Harper.

Tomkins, S. S. (1963). Left and right: A basic dimension of ideology and personality. In R. W. White (Ed.), The study of lives (pp. 388-411). Chicago: Atherton.

Tomkins, S. S. (1987). Script theory. In J. Aronoff, A. I. Rabin, \& R. A. Zucker (Eds.), The emergence of personality (pp. 147-216). New York: Springer.

Weber, C., \& Federico, C. M. (2007). Interpersonal attachment and patterns of ideological belief. Political Psychology, 28, 389-416.

Wills, G. (2007). Head and heart: American Christianities. New York: Penguin.

Winter, D. G. (2007). The role of motivation, responsibility, and integrative complexity in crisis escalation: Comparative studies of war and peace crises. Journal of Personality and Social Psychology, 92, 920-937. 